Advances in

Disease Vector Research 


\title{
Advances in Disease Vector Research
}

\author{
Edited by
}

Kerry F. Harris

Virus Vector Laboratory, Department of Entomology, Texas A\&M

University, College Station, Texas 77843, USA

\author{
Editorial Board \\ Willy Burgdorfer \\ Epidemiology Branch, Rocky Mountain Laboratories, Hamilton, \\ Montana 59840, USA
}

Richard I.B. Francki

Virus Laboratory, The University of Adelaide, Waite Agricultural

Research Institute, Glen Osmond, South Australia 5064

\section{Edouard Kurstak}

Comparative Virology Research Group, Department of Microbiology and Immunology, Faculty of Medicine, University of Montreal, Montreal H3C 3J7, Canada

John J. McKelvey, Jr.

Associate Director of Agricultural Sciences for the Rockefeller Foundation (Retired), Richfield Hill Farm, Route 1, Box 144-A, Richfield Springs, New York 13439, USA

\section{Benny Raccah}

Department of Virology, The Volcani Center, Bet Dagan, Israel

\section{Robert K. Washmo}

Department of Entomology, University of California at Davis, Davis, California 95616, USA

Robert R. Whitcomb

Plant Disease Vector Laboratory, SEA-USDA, B465, Beltsville, Maryland 20705, USA

\section{Telford $H$. Work}

Department of Medical Microbiology and Immunology, School of Medicine, University of California at Los Angeles, Los Angeles, California 90024, USA 


\section{Advances in Disease Vector Research}

Volume 8

Edited by Kerry F. Harris

With Contributions by

T.V. Barrett D.T. Brown T.R. Burkot

C.R. Davies R.C. Gergerich R. Gothe

L.D. Jones M.L. Miller M. Mogi A.W.H. Neitz

P.A. Nuttall H.A. Scott T. Sota R.A. Wirtz

Springer-Verlag

New York Berlin Heidelberg London

Paris Tokyo Hong Kong Barcelona 
Kerry F. Harris

Virus Vector Laboratory

Department of Entomology

Texas A\&M University

College Station, TX 77843, USA

Volumes 1 and 2 of Current Topics in Vector Research were published by Praeger Publishers, New York, NY.

ISSN: 0934-6112

Printed on acid-free paper.

(C) 1991 Springer-Verlag New York Inc.

Softcover reprint of the hardcover 1st edition 1991

Copyright is not claimed for works by U.S. Government employees.

All rights reserved. This work may not be translated or copied in whole or in part without the written permission of the publisher (Springer-Verlag New York, Inc., 175 Fifth Avenue, New York, NY 10010, USA), except for brief excerpts in connection with reviews or scholarly analysis. Use in connection with any form of information storage and retrieval, electronic adaptation, computer software, or by similar or dissimilar methodology now known or hereafter developed is forbidden.

The use of general descriptive names, trade names, trademarks, etc., in this publication, even if the former are not especially identified, is not to be taken as a sign that such names, as understood by the Trade Marks and Merchandise Marks Act, may accordingly be used freely by anyone.

Typeset by Best-set Typesetter Ltd., Quarry Bay, Hong Kong.

\section{1}




\section{Preface}

In Chapter 1, Rose Gergerich and Howard Scott review their most recent research on the mechanism of virus transmission by leaf-feeding beetles. Based on these studies, the authors conclude that vector specificity is determined by virus-plant interactions that occur after virus in beetle regurgitant is deposited at a feeding-wound site. This form of vector specificity appears unique to beetle-borne viruses in that it is ultimately controlled by virusplant rather than virus-vector interactions. An important step in the unraveling of the mystery surrounding the transmission process was the development of a gross-wound inoculation technique. The latter produces a wound site and introduces virus in a manner similar to the feeding process of viruliferous beetles. By combining this technique with grosswound inocula containing purified virus and beetle regurgitant or RNase, Gergerich and Scott were able to demonstrate that beetle regurgitant, and specifically the RNase in regurgitant, can selectively prevent infection by viruses not transmitted by beetles. Beetle transmissible viruses can translocate (via the xylem) from gross-wound sites and, subsequently, infect unwounded plant cells, whereas non-beetle transmissible viruses cannot. Future research efforts will be directed at determining the bases for these differences and the mechanism by which beetle-transmissible viruses initiate cell infection following translocation.

Patricia Nuttall, Linda Jones and Clive Davies discuss, in Chapter 2, the role of arthropod vectors in arbovirus evolution. The co-evolution of arthropod-borne viruses of vertebrates (arboviruses) with their arthropod vectors may span at least 100 million years. Today some 500 viruses are listed in the "International Catalogue of Arboviruses." Many of the arthropod vectors of these viruses also act as resevoir hosts, maintaining the arbovirus infection for relatively long periods. These considerationsevolutionary history, arbovirus diversity, and maintenance of arbovirus infections - indicate that arthropod vectors play a major role in arbovirus evolution.

The authors consider that the evolutionary role of the arthropod can be distinguished at two levels: as a medium in which genetic changes (the 
building blocks of evolution) occur, and as a selective pressure that drives the course of arbovirus evolution. Changes in viral genotype take place during virus replication. The foci of infection within the arthropod vector represent the anatomical basis of arbovirus evolution. For example, the gut of mosquitoes and ticks is implicated as the site of virus reassortment (a means of rapid virus evolution through the exchange of viral genes). Target sites of infection within the arthropod vector also act as selection pressures, e.g., the gut barrier, gut release barrier, salivary gland barrier, etc. Such barriers must be overcome by the infecting virus as a prelude to successful virus transmission to a new host. The importance of transmissibility implies selection for arboviruses of relatively low virulence in their vector and comparatively high virulence in their vertebrate host. This contrasts with the established view that evolution favors reduced virulence. Other examples of vector-mediated selection pressures relate to interspecific and intraspecific vector variation. For example, vectors having a high threshold of infection will select for virus strains that induce high levels of viremia. Comparisons of the roles of vector and vertebrate hosts suggest that the arthropod vector has more opportunities than the vertebrate host to influence the course of arbovirus evolution.

In Chapter 3, Motoyoshi Mogi and Teiji Sota discuss the many parameters of integrated control of mosquitoes and mosquito-borne diseases in ricelands. The flooded land required for the optimal growth of high-yield rice varieties also provides mosquito vectors of human diseases such as malaria, filariasis, and viral encephalitis with extensive larval habitats. The authors present their treatise in three parts, beginning by pointing out similarities and dissimilarities between integrated control of economic pests and human disease vectors. Next, they describe the characteristics of rice agroecosystems as mosquito habitats and briefly review methods for riceland mosquito control. In the final section, Mogi and Sota focus on livestock management, hopefully to stimulate additional research into this very important but least explored component of integrated control of mosquitoes and mosquito-borne diseases in ricelands. The authors close by noting that the persistence of mosquito-borne diseases in ricelands is a consequence of the overall effects of environmental components and human factors which together provide for all essential links in a pathogen transmission cycle. Thus, although certainly worldwide in scope, mosquitoborne disease problems in ricelands are also distinctly local and require a full awareness of local situations for successful resolution.

Bob Wirtz and Thomas Burkot present, in Chapter 4, a comprehensive overview of traditional and more recent methodologies for detecting malarial parasites in mosquitoes. The identification of sporozoite-infected mosquitoes is an integral part of many malaria epidemiological studies. Historically, this has been accomplished by dissection of freshly killed mosquitoes and examination of the salivary glands-a labor intensive, time-consuming, costly process requiring experienced technicians which 
still does not permit species identification of the parasite. The development of new biotechnology-based methods has significantly reduced both time and cost factors while simplifying and improving our ability to detect and identify sporozoites.

The latter is best exemplified by the production and use of speciesspecific, anti-circumsporozoite protein monoclonal antibodies (MAbs) in immunofluorescent antibody or immunohistochemical assays. Immunofluorescent antibody assays permit species identification of salivary gland sporozoites from field collected mosquitoes, whereas immunohistochemical assays make such tests possible in many more laboratories by eliminating the need for a fluorescent microscope. Coupling MAbs with enzyme-linked immunosorbent assays (ELISAs) and immunoradiometric assays permits the testing of large numbers of dried mosquitoes and lessens the logistic burden associated with many field studies. Indeed, the distribution of ELISA kits to scientists without resources to develop their own assays is one of the most successful examples of the transfer of biotechnology to developing countries, greatly facilitating comparisons of data from different geographic regions. However, before such assays are used on field-collected mosquitoes, it is essential to verify that the target epitope of the MAb, present on the sporozoite, is conserved in new study areas. The authors are confident of a continuing increase in the use of nucleic acid probes in malaria research. Ribosomal RNA (rRNA) probes offer tremendous potential for the development of diagnostic systems for the quantitative and species-specific detection of both mosquito vectors and malaria parasites. DNA probes will continue to be valuable but await adaptation to nonradioisotopic detection systems to become routinely useful in field laboratories. Wirtz and Burkot also note that, except for transmission studies, establishing the vector status of an anopheline mosquito requires the combined use of traditional and more recent technologies for sporozoite detection and identification.

In Chapter 5, Mary Miller and Dennis Brown review the study of alphavirus infection in vertebrate and mosquito cell culture. They summarize recent reports on virus entry into vertebrate cells and replication of viral RNA during the early stages of infection. Evidence of host cell participation in both vertebrate and invertebrate cells is reviewed with emphasis on the differences in host cell response between the two phylogenetically distinct systems. Molecular genetic approaches to understanding the process of alphavirus infection are also described. The authors end their chapter with a discussion of viral morphogenesis and cytopathic response to infection in mosquito cells, and the establishment of the persistently infected state in insect culture. Their emphasis is on the importance of characterizing alphavirus infection in insect cells as models for controlling the pathogenic viruses that insects vector.

Advances in triatomine bug ecology in relation to Chagas' disease are discussed in Chapter 6. Since all of the approximately 116 species of 
Triatominae are directly or indirectly of interest in the study of Chagas' disease, Toby Barrett, the author, begins by considering the individual species according to their taxonomic groupings. This unbiased arrangement reveals that ecology and distribution are often well correlated with systematics. Additionally, it calls attention to those groups for which our ecological knowledge is most inadequate and avoids the danger of confusing degrees of synanthropy with stages of an evolutionary trend. Barrett discusses recent developments in the population dynamics of domestic vectors along with work on the influence of human ecology on vector populations. The author provides a synopsis of the current status of research, with directions to the literature on the different aspects of a rather wide topic, while examining critically some of the conclusions that have been drawn from previous work. The possible effects of environmental alterations on triatomine populations are briefly considered, as are the implications of advances in population genetics and molecular taxonomy for ecological studies.

Past achievements and recent advances in the pathogenesis and etiology of tick paralyses are discussed in Chapter 7. The authors, Rainer Gothe and Albert Neitz review the past 60 years of progress in research and list 60 tick species belonging to 10 genera as potential paralysis inducers. Pathomechanisms and etiology of tick paralyses, however, are only investigated in the disease syndrome caused by Argas (Persicargas) walkerae, Dermacentor andersoni and D. variabilis, Rhipicephalus evertsi evertsi and Ixodes holocyclus. But these tick species are of medical importance: I. holocyclus of Australia and $D$. andersoni and $D$. variabilis of North America in human medicine, and these same species as well as $R$. evertsi evertsi and $A$. walkerae of the Ethiopian faunal region in veterinary medicine.

I thank the authors for their outstanding contributions and their patience and support while working with me to bring Volume 8 of Advances in Disease Vector Research to a successful and rewarding conclusion. And, as always, the encouragement and technical assistance of the members of the Editorial Board and the staff of Springer-Verlag are humbly acknowledged and sincerely appreciated.

Kerry F. Harris 


\section{Contents}

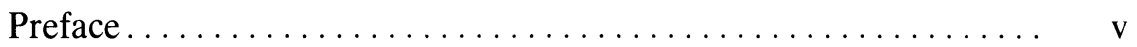

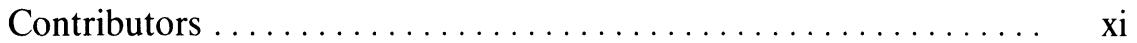

Contents for Previous Volumes $\ldots \ldots \ldots \ldots \ldots \ldots \ldots \ldots$ xiii

1 Determinants in the Specificity of Virus Transmission by Leaf-feeding Beetles .......................... 1 Rose C. Gergerich and Howard A. Scott

2 The Role of Arthropod Vectors in Arbovirus Evolution ....... 15 Patricia A. Nuttall, Linda D. Jones, and Clive R. Davies

3 Towards Integrated Control of Mosquitoes and Mosquito-borne Diseases in Ricelands.............................. 47 Motoyoshi Mogi and Teiji Sota

4 Detection of Malarial Parasites in Mosquitoes ............... 77 Robert A. Wirtz and Thomas R. Burkot

5 Alphavirus Infection in Cultured Tissue Cells . . . . . . . . . . 107 Mary L. Miller and Dennis T. Brown

6 Advances in Triatomine Bug Ecology in Relation

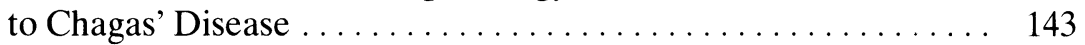
Toby V. Barrett

7 Tick Paralyses: Pathogenesis and Etiology . . . . . . . . . . . . . . 177 Rainer Gothe and Albert W.H. Neitz

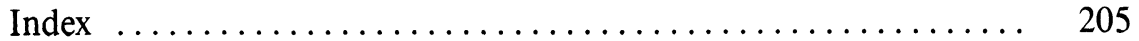




\section{Contributors}

Toby V. Barrett

Departamento da Ciências de Saúde, Instituto Nacional de Pesquisas da Amazônia, 69083 Manaus-AM, Brazil

Dennis T. Brown

Cell Research Institute and Department of Microbiology, The University of Texas at Austin, Austin, Texas 78713, USA

Thomas R. Burkot

Tropical Health Program, Queensland Institute of Medicial Research, Bramston Terrace, Herston, Brisbane, Queensland 4006, Australia

Clive R. Davies

Department of Medical Parasitology, London School of Hygiene \& Tropical Medicine, UK

Rose C. Gergerich

Department of Plant Pathology, University of Arkansas, Fayetteville, Arkansas 72701, USA

\section{Rainer Gothe}

Institute for Comparative Tropical Medicine and Parasitology, University of Munich, W-8000 Munich 40, Germany

Linda D. Jones

NERC Institute of Virology \& Environmental Microbiology, Oxford, OX 1 3SR, UK

\section{Mary L. Miller}

Cell Research Institute and Department of Microbiology, The University of Texas at Austin, Austin, Texas 78713, USA

Motoyoshi Mogi

Division of Parasitology, Department of Microbiology, Saga Medical School, Nabeshima, Saga 849, Japan 
xii Contributors

Albert W.H. Neitz

Department of Biochemistry, University of Pretoria, Pretoria 0002, Republic of South Africa

\section{Patricia A. Nuttall}

NERC Institute of Virology \& Environmental Microbiology, Oxford, OX 1 3SR, UK

Howard A. Scott

Department of Plant Pathology, University of Arkansas, Fayetteville, Arkansas 72701, USA

\section{Teiji Sota}

Division of Parasitology, Department of Microbiology, Saga Medical School, Nabeshima, Saga 849, Japan

\section{Robert A. Wirtz}

Department of Entomology, Walter Reed Army Institute of Research, Washington D.C. 20307, USA 


\section{Contents for Previous Volumes}

\section{Volume 1}

1 Historical Perspectives on Yellow Fever Vector Research Hugh H. Smith and Wilbur G.Downs

2 Genetic Variation in the Ability of Insects to Transmit Filariae. Trypanosomes, and Malarial Parasites

C.F. Curtis and P.M. Graves

3 Mosquito Vector Competence and Arboviruses Carl J. Mitchell

4 The Physiological Control of Mosquito Host-seeking Behavior Marc J. Klowden

5 Host-Parasite Relationships of Trypanosomatidae in Vectors D.H. Molyneux

6 Maize Rayado Fino Virus: Evolution with Plant Host and Insect Vector R. Gámez and P. León

7 Transmission and Epidemiology and Lettuce Necrotic Yellows Virus J.W. Randles

8 Utilization of Insect Tissue Culture in the Study of the Molecular Biology of Plant Viruses

H.T. Hsu, D.L. Nuss, and G. Adam

9 The Function of Tick Salivary Glands

William R. Kaufman

10 Host Immunity of Tick Bite

Stephen K. Wikel

11 Feeding Processes of Virus-transmitting Nematodes W.M. Robertson and $U$. Wyss

12 Insect-induced Phytotoxemias: Damage, Tumors, and Galls A.F.G. Dixon 


\section{Volume 2}

1 The Controversy Regarding Multiplication of Some Plant Viruses in Their Insect Vectors

L.M. Black

2 Ross River Virus and Epidemic Polyarthritis

Ian D. Marshall and John A.R. Miles

3 Transovarial Transmission of Arboviruses in Their Invertebrate Vectors Robert B. Tesh

4 Vertical Transmission of Spotted Fever Group and Scrub Typhus Rickettsiae Willy Burgdorfer

5 Transmission Mechanism of Mycoplasma-like Organisms by Leafhopper Vectors

Ramesh C. Sinha

6 Epidemiology and Vectors of Plant Reolike Viruses

Maurizio Conti

7 Leafhopper- and Aphid-borne Viruses Affecting Subtropical Cereal and Grass Crops

R.S. Greber

8 Zoogeographical Distribution of Whiteflies

Laurence A. Mound

9 Tick Paralyses: Reasons for Appearing During Ixodid and Argasid Feeding R. Gothe

10 Tick Pheromones

Daniel E.Sonenshine

\section{Volume 3}

1 Ecology of Arboviruses and Their Vectors in Australia Brian H. Kay and Harry A. Standfast

2 Current Research on Dengue Duane J.Gubler

3 Systems Approaches for Management of Insect Rice Diseases Keizi Kiritani, Fusao Nakasuji, and Shun'ichi Miyai

4 Aphid Vector Monitoring in Europe Yvon Robert

5 Nepoviruses of the Americas Richard Stace-Smith and Donald C. Ramsdell

6 Virus Replication, Translation, and Assembly of Nepoviruses Donald C. Ramsdell 
7 Soil-borne Viruses of Plants

Chuji Huruki and David S. Teakle

8 Immunoelectron Microscopy of Plant Viruses and Mycoplasma

Yogesh C. Paliwal

\section{Volume 4}

1 Diapause and Related Phenomena in Culex Mosquitoes: Their Relation to Arbovirus Disease Ecology

Bruce F. Eldridge

2 New World Vectors of Leishmaniases

David G. Young and Phillip G. Lawyer

3 Whitefly Transmission of Plant Viruses

James E. Duffus

4 Virus-Membrane Interactions Involved in Circulative Transmission of Luteoviruses by Aphids

Frederick E. Gildow

5 Ecology and Evolution of Leafhopper-Grass Host Relationships in North American Grasslands

Robert F. Whitcomb, James Kramer, Michael E. Coan, and Andrew L. Hicks

6 Feeding Strategies and the Guild Concept Among Vascular Feeding Insects and Microorganisms

David W. Tonkyn and Robert F. Whitcomb

\section{Volume 5}

1 Juvenile Hormone Regulation of Biting Behavior and Egg Development in Mosquitoes

Roger Meola and Janice Readio

2 Tick-borne Virus Infections of Marine Birds Claude E.Chastel

3 Tick Paralysis, Particularly Involving Ixodes holocyclus and Other Ixodes Species

Bernard F. Stone

4 Tick Tissue and Cell Culture in Vector Research Timothy J. Kurtti, Ulrike G. Munderloh, and Gilbert G. Ahlstrand

5 Leafhopper Cell Cultures as a Means for Phytoreovirus Research Ikuo Kimura and Toshihiro Omura

6 Contributions of Cladistic Analyses to Leafhopper Vector Complexes Bruce W. Triplehorn 
7 Epidemiology and Control of Fiji Disease Virus of Sugarcane Colin C. Ryan

8 Tropical Maize Pathogens and Their Associated Insect Vectors James H. Tsai and Bryce W. Falk

9 Tomato Spotted Wilt Virus: Thrips Transmission and Control D.V.R. Reddy and John A. Wightman

10 Virus-Pollen Interactions

J. Ian Cooper, Steven E. Kelley, and the late Peter R. Massalski

11 Correlation Between Stylet Paths Made During Superficial Probing and the Ability of Aphids to Transmit Nonpersistent Viruses

Dennis Lopez-Abella, R.H.E. Bradley, and Kerry F. Harris

\section{Volume 6}

1 Ribosomal RNA Genes of the Anopheles gambiae Species Complex Frank H. Collins, Susan M. Paskewitz, and Victoria Finnerty

2 Neuroendocrine and Midgut Endocrine Systems in the Adult Mosquito Mark R. Brown and Arden O. Lea

3 Gametocytemia and Infectiousness in Falciparum Malaria: Observations and Models Jerry Nedelman

4 Some Aspects of the Biology of Phlebotomine Sandfly Vectors Richard D. Ward

5 Vector-Spirochete Relationships in Louse-borne and Tick-borne Borrelioses with Emphasis on Lyme Disease

Willy Burgdorfer and Stanley F. Hayes

6 Distribution of Viruses and Their Nematode Vectors Giovanni P. Martelli and Charles E. Taylor

7 Detecting Plant Viruses in Their Vectors Roger T. Plumb

8 Insect-borne Viruses of Rice Hiroyuki Hibino

9 Homopteran Transmission of Xylem-inhabiting Bacteria Alexander H. Purcell

10 Plant Pathogenic Spiroplasmas and Their Leafhopper Vectors Deborah A. Golino and George N. Oldfield

11 Semipersistent Transmission of Viruses by Vectors with Special Emphasis on Citrus Tristeza Virus

Benjamin Raccah, Chester N. Roistacher, and Sebastiano Barbagallo 


\section{Volume 7}

1 Transmission of Velvet Tobacco Mottle Virus and Related Viruses by the Mirid Cyrtopeltis nicotianae

Karen S. Gibb and John W. Randles

2 Factors Influencing Aphid Population Dynamics and Behavior and the Consequences for Virus Spread Nick Carter and Richard Harrington

3 Cyclic Epidemics of Aphid-borne Potato Viruses in Northern Seed-potatogrowing Areas

Richard H. Bagnall

4 Interactions Between Barley Yellow Dwarf Virus Infection and Winter-stress Tolerance in Cereals

Christopher J. Andrews and Ramesh C. Sinha

5 Artificial Diets for Blood-feeding Insects: A Review John R. DeLoach and George Spates

6 Transmission of African Trypanosomiasis: Interactions Among Tsetse Immune System, Symbionts, and Parasites Ian Maudlin

7 Mosquito Spiroplasmas Claude Chastel and Ian Humphery-Smith 